Relato de Experiência

\title{
Recreação Esportiva e seus desafios corporais no Complexo do Alemão
}

\author{
Ângela Ferreira Tavares ${ }^{1}$ \\ Vera Lúcia de Meneses Costa ${ }^{1}$ \\ Manoel José Gomes Tubino ${ }^{2}$ \\ ${ }^{1}$ Universidade Castelo Branco, Rio de Janeiro, RJ, Brasil \\ 2 (In memorian)
}

\begin{abstract}
Resumo: A Recreação Esportiva, uma das propostas do Projeto "Cultura Corporal Esporte e Lazer no Complexo do Alemão", foi aplicada pela co-autora deste artigo na comunidade da Grota e teve por objetivos: Identificar crianças de 7 a 12 anos afastadas da escola; Desenvolver os fundamentos básicos das modalidades de esportes coletivos e da ginástica artística, 5 vezes na semana com duração de 1 hora para cada sessão com o enfoque na recreação; e desenvolver temas pedagógicos bimestrais para buscar o melhor comportamento das crianças. Resultados: 16 alunos do projeto afastados da escola foram encaminhados à $4^{\mathrm{a}} \mathrm{CRE}$; os pais atribuíram melhoras nas atitudes de seus filhos à intervenção do projeto; valorizou-se a presença dos menos habilidosos diante do grupo em diferentes momentos da aula. Conclusão: A intervenção da Educação Física permite potencializar o jovem morador da área de risco e minimizar possíveis problemas em suas buscas por novos ideais de vida.
\end{abstract}

Palavras-chave: Recreação. Modalidades Esportivas. Psicomotricidade.

\section{Recreational Sports and the related bodies' challenges in the Complexo do Alemão}

\begin{abstract}
The Recreational Sports, one of the proposals of project called "Corporal Culture, Sports and Leisure in the Complexo do Alemao", was applied by the co-author of this article to the Grota Community and has the following goals: identify 7 to 12 years-old children who were away from school, develop fundamental basics of collective sports modalities besides artistic gymnastic throughout a one-hour session, five times a week, with a focus on recreation, and develop bimonthly educational themes to obtain children better behavior. Results: sixteen project participants who were out of school were sent to $4^{\mathrm{a}} \mathrm{CRE}$, parents attributed their children attitudes improvement to the project intervention, and the presence of less skilled children were valued in the group over different classes moments. Conclusion: The Physical Education intervention allows young risk-area residents to develop their potentials and to minimize their possible problems in their search for new ideals of life.
\end{abstract}

Key Words: Recreational. Sportive Modalities. Psychomotricity.

\section{Introdução}

Este artigo trata do uso da recreação esportiva como ferramenta pedagógica na socialização de conhecimentos em processo de implantação e acompanhamento de atividades desenvolvidas na comunidade do Complexo do Alemão no Município do Rio de Janeiro, tendo como alvo principal a melhoria das condições de vida de crianças e jovens e de suas relações na comunidade.

Recreação provém de recreare, que significa "criar novamente" no sentido positivo, ascendente e dinâmico (FERREIRA, 2006). Vanja Ferreira (2006) valoriza a recreação para a formação do caráter no enriquecimento da personalidade, na moral que interfere na educação integral da criança e acredita que a atividade recreativa desenvolve as características físicas, psíquicas, motoras, o domínio do corpo, o espírito cooperativo de grupo capaz de fortalecer as relações humanas e, principalmente, criar o gosto pela atividade física que prepara a criança para as aulas de Educação Física e de esporte.

É importante que os profissionais de Educação Física reconheçam a recreação e o esporte como ferramentas aliadas na construção da personalidade, na educação e no desenvolvimento da criança. Com esta proposta de ensino a Educação Física poderá interferir também no adequado relacionamento social para desviar a juventude de passatempos nocivos à formação do cidadão conscientes de seu papel na sociedade.

D'Amico e D'Amico (2007) reconhecem que a atividade física, desde os primeiros anos de vida, é elemento básico para um desenvolvimento humano saudável. A prática esportiva ajuda a prevenir a obesidade e, por conseqüência, a uma série de possíveis doenças ao longo da vida. Tais atividades, quando desenvolvidas de modo 
recreativo, podem desencadear motivações, atender necessidades individuais relevantes em relação ao movimento e produzir benefícios psicofisiológicos plenamente prazerosos. Nesse sentido, pode-se dizer que a família se apresenta como a primeira responsável pelo comportamento de seus filhos, utilizando o tempo e os recursos a serem investidos nos estudos, no esporte e na alimentação.

Tendências negativas de desvalorização da Educação Física, até mesmo em países desenvolvidos, se manifestam na contramão da recomendação da UNESCO e revelam a ausência de políticas de prevenção da saúde por meio de programas de atividades físicas presentes nas áreas da educação, da saúde, do planejamento ambiental, do esporte, da educação física e da recreação que atendam à população.

Manifestos de organismos mundiais e nacionais sugerem reflexões e intervenções da Educação Física quanto a seus compromissos em relação à educação, à saúde, ao turismo e ao meio ambiente tais como: (a) Carta Brasileira de Educação Física (CONFEF, 2000); (b) Agenda 21 (Earth Summit, Rio de Janeiro, 1992); (c) Manifesto 2000 - Por uma Cultura de Paz e Não Violência (Grupo de Prêmios Nobel, 1998): (d) Carta Internacional de Educação Física e Esporte (UNESCO, 1978); (e) Carta dos Direitos da Criança no Esporte (Panathlon, Avignone, 1995); (f) Carta Brasileira de Esporte Educacional (SEED,MEC, 1989); (g) World Summit on Physical Education (ICSSP, 1999); (h) Declaração de Punta del Este do III Encontro de Ministros e Responsáveis pelo Esporte e Educação Física (UNESCO, III MINEPS,1999); (i) Manifesto Mundial FIEP de Educação Física 2000 (FIEP, 2000).

Todos os documentos reconhecem a Educação Física como um dos direitos humanos fundamentais. Com a regulamentação da profissão no Brasil (Lei 9696/ 98), os profissionais de Educação Física melhor qualificados têm seus interesses defendidos por Conselhos instituídos que fazem a política de informação, controle e organização da intervenção profissional capaz de conquistar espaços e a credibilidade diante da população do país. Passam a existir ações comprometidas com o crescimento pessoal, que contribuem para a melhoria da saúde; do desenvolvimento mental, sócio-cultural e espiritual; e para a qualidade de vida do indivíduo. Esta área conduz a um estilo de vida ativo e compreende possibilidades de movimento e educa para o entendimento da importância de como e onde deve ser utilizada e por quem deve ser administrada para ser uma experiência singular por tratar-se da educação do corpo, no qual se inscrevem todas as ações humanas. Investir em educação física nas perspectivas de saúde e de recreação é minimizar futuros problemas de sedentarismo e outras doenças agregadas à sociedade, favorecendo-lhe o bem estar físico e mental.

O esporte, enquanto uma forma de exercício da Educação Física, quando desempenhado a partir de uma intenção educacional, é uma atividade cultural, instrutiva e pedagógica, destacada como um meio para promover educação, saúde, desenvolvimento e paz.

A iniciação esportiva, realizada por meio de jogos recreativos, tem valor educativo para o corpo por apresentar ludicamente o desenvolvimento dos domínios cognitivo, afetivo, psicomotor e moral na criança. A competição faz parte da condição humana e vem se aprimorando ao longo dos tempos por valores e regras morais de "fair play" e por ser capaz de alcançar êxito em situações de tensão. Problematizá-la em recreação esportiva favorece a construção de outras possibilidades de esporte que considere a participação, a criatividade e cooperação. A organização tática que a criança adquire ao jogar e/ ou competir é capaz de desenvolver a sua condição de raciocinar lógica e rapidamente, além de, a cada investida, avaliar as suas escolhas, para utilizar a sua capacidade de tomar decisões por meio dos resultados alcançados.

Parlebas (1988), em estudos sobre a lógica interna dos jogos, diz que a organização dos mesmos se dá sob a forma de um sistema, para fomentar os comportamentos lúdicos que engendram as situações motrizes que aí se desencadeiam.

O melhor desempenho na execução de cada jogada vai depender da capacidade de os jogadores superarem as suas limitações técnicas e melhorarem o domínio do próprio corpo para poderem cooperar com os companheiros, tomar decisões em ação e obedecer à determinada tática do jogo de oposição. A estratégia escolhida para progredir com a bola e de jogar sem ela vai interferir no posicionamento do corpo do jogador em relação ao seu espaço de jogo e à bola, material mediador da comunicação corporal que se instaura no campo de jogo. Assim, a tática aplicada pode ser decisiva e deve acontecer de acordo com as habilidades exigidas em cada esporte coletivo ou até mesmo individual no caso de aprender a dividir seus esforços durante a prova ou ainda investir em um determinado golpe durante uma luta. Em qualquer situação de 
competição, o indivíduo deve aprender a manifestar as suas intenções em função de uma tática organizada por ele mesmo ou pela equipe para ser eficiente na busca do seu sucesso na situação motriz.

O jogo esportivo e as atividades recreativas são formas que mobilizam a natureza e as condições emocionais do indivíduo, tais como a surpresa, a emoção, a curiosidade e o espírito de competição. Costuma-se dizer que durante o jogo a criança revela o seu "eu" verdadeiro, aquilo o que é verdadeiramente sem máscaras e sem artifícios.

Para Schiller (1995), o homem só é verdadeiramente homem quando joga. As ações motrizes de comunicação e de contra comunicação podem ser interpretadas quando o indivíduo aprende a lidar com a competição em que um ajuda ao outro por cooperação para atingirem o mesmo ideal e aprende, também, as propostas do jogo de oposição, onde competidores jogam contra adversários e contra seus limites, respeitando-os.

Através da recreação, torna-se possível obter a motivação e a intensidade do prazer que a criança sente ao recrear-se capaz de comprovar se foram atendidas as suas necessidades. Cabe ao professor de Educação Física perceber 0 tempo de duração para cada estímulo e saber interpretar o feedback apresentado por seus alunos para seguir o planejamento ou adaptá-lo para melhor atender às necessidades da turma. O professor deve encaminhar as atividades recreativas com o devido cuidado de evitar que elas oportunizem aos praticantes sentimentos de frustração, de impotência ou de repressão.

O adulto deve respeitar o momento e a necessidade da criança brincar para se desenvolver, amadurecer e aprender a explorar as ferramentas que o universo infantil tem a oferecer. Em sua natureza, o lúdico é tão importante que se não tiver um brinquedo disponível, ela vai explorar situações que podem ser perigosas para a sua segurança. Brincar para poder aprender a jogar e jogar para poder realizar suas fantasias no mundo do "faz de conta", embora todas as apostas sejam contra o jovem que reside em comunidade de baixa renda. Assim, durante uma sessão de Recreação Esportiva, ela finge em ser um "Romário" ou "Ronaldo" enquanto faz um gol, um "Oscar" enquanto dribla uma bola ou um "Serginho", oriundo da favela, líbero consagrado no mundo através do voleibol brasileiro. Os estímulos são diversificados e oportunos para que o aluno busque novas experiências e coloque a sua criatividade à prova com movimentos livres e espontâneos, e sem a necessidade do resultado com a melhor performance na execução do movimento, muitas vezes, engessado pelo fundamento de apenas um determinado esporte.

\section{O relato de uma experiência}

De maio de 2003 a novembro de 2004, a professora Ângela Tavares, co-autora deste artigo, representou o Curso de Educação Física de uma Instituição de Ensino Superior nas comunidades do subúrbio da Leopoldina, Zona Norte do Rio e também ministrava aulas das disciplinas de Psicomotricidade e Pesquisas e Práticas Pedagógicas na mesma Instituição, cuja meta era a "Responsabilidade Social" e participação no desenvolvimento da região. A professora coordenava propostas de educação através do esporte e o projeto "Cultura Corporal, Esporte e Lazer" foi implantado na Grota Complexo de Favelas do Alemão $^{1}$, comunidade considerada das mais violentas da cidade já que concentra cerca de $40 \%$ dos crimes cometidos no Rio. A região já foi uma importante área industrial, mas ao longo dos anos foi perdendo espaços para a violência e, atualmente, é uma das principais preocupações do poder público no Rio. A fuga das indústrias gerou o empobrecimento local e deu lugar a uma área marcada pela pelos confrontos entre traficantes rivais e entre a polícia e bandidos. Após a entrada da cocaína nos morros cariocas, a partir dos anos 80, cresceu 0 comércio de armas de guerra e os bandidos mais jovens e descendentes das facções de Orlando (um dos chefes da maior facção criminosa do estado assassinado em 1994) e Uê (chefe do morro do Adeus) montaram a facção ainda mais violenta, dando início à guerra que, até outubro de 2007, matou cerca de 30 mil pessoas na capital, segundo o site de O GLOBO.

De acordo com o senso de 2000, o Complexo do Alemão tem 65 mil habitantes distribuídos em 18.245 domicílios e nos $3 \mathrm{KM}^{2}$ de área reúne 13 favelas: Morro Alemão, Grota, Nova Brasília, Alvorada, Alto Florestal, Itararé, Morro Baiana, Morro Mineiro, Morro da Esperança, Joaquim de Queiroz, Vila Cruzeiro, Morro das Palmeiras e Morro do Adeus. A área é compreendida pelos

\footnotetext{
1 Segundo histórias sobre o surgimento do Complexo do Alemão, assim nomeado, devido à presença do morador polonês loiro Leonard Kaczmarkiewicz que deixou a Polônia na década 20 para adquirir terras na Serra da Misericórdia na região rural da Zona da Leopoldina, virou ponto de referência para os moradores das favelas vizinhas que se referiam ao local lembrando as características físicas de seu proprietário. Em 1951 Leonard dividiu o terreno para ser dividido em lotes e serem vendidos para operários da região. A ocupação desordenada dos morros incentivada pelo primeiro governo Brizola contribuiu para o começo do processo de favelização do bairro.
} 
bairros de Inhaúma, Bonsucesso, Ramos, Olaria e Penha.

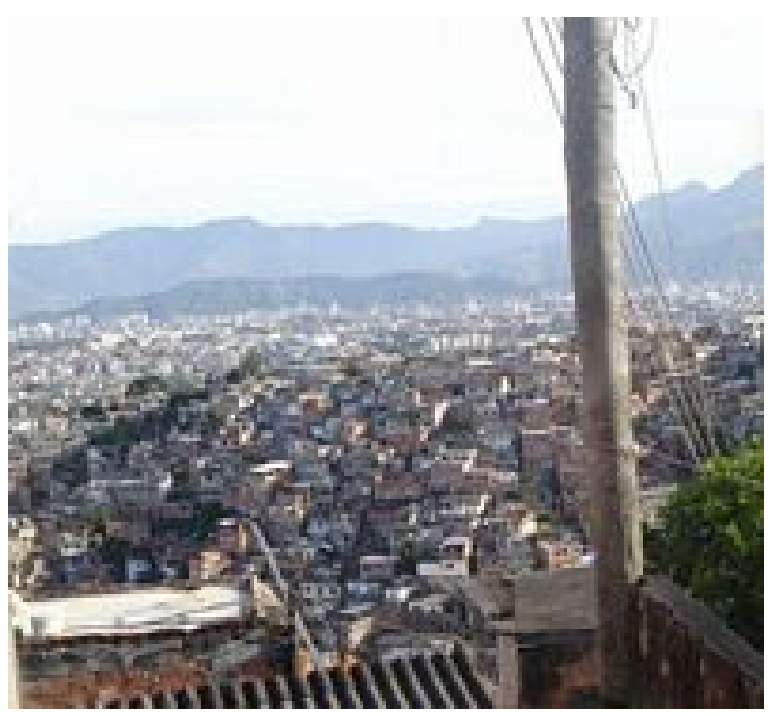

A Recreação Esportiva fazia parte do Projeto "Cultura Corporal Esporte e Lazer no Complexo do Alemão" e teve por objetivos: (a) Identificar as crianças que estavam fora da escola e reencaminhá-las; (b) desenvolver temas pedagógicos a cada bimestre, de acordo com a época do ano ou a necessidade observada junto ao seu público alvo para acompanhar o processo de aprendizagem e perceber as dificuldades cognitivas, afetivas e psicomotoras durante as atividades recreativas; (c) Oferecer campo de observação e atuação orientada aos estudantes de Educação Física da Instituição de Ensino Superior responsável pelo projeto nas comunidades de Bonsucesso e adjacências; (d) desenvolver as qualidades físicas predominantes em cada sessão através dos fundamentos básicos da Ginástica Artística, do Voleibol, do Handebol, do Futsal e do Basquetebol presentes em todas as aulas.

Houve necessidade de adaptação às condições oferecidas pelo local, isto é, não havia quadra ou marcações características para as práticas esportivas. Era um salão de $200 \mathrm{~m}^{2} \mathrm{com}$ 3 pilares no centro, localizado no $2^{\circ}$ andar do galpão onde funcionavam, em outros andares, projetos de reforço escolar e de cursos profissionalizantes, organizados pela Organização Não Governamental "S.O.S Comunidades", que tinha parceria com a mesma IES e ajudava a divulgar o projeto do Curso de Educação Física no interior da "comunidade".

Um muro separava o galpão, local em que as atividades de recreação esportiva amenizavam as dores e traumas que aconteciam todos os dias, do outro lado, onde tiros e até mortes contrastavam com a alegria e a descontração das crianças que brincavam. Nesse contexto, a violência e a falta de recursos habitam sem piedade, comprometendo a vida, a paz, a segurança e o futuro de seus habitantes. Comunidade de baixa renda, chamada pelos moradores do "asfalto" de favela, é um local ocupado por migrantes, em sua maioria, nortistas e nordestinos que chegam com a esperança de trabalhar na cidade grande e, em busca de oportunidades de emprego, acabam contribuindo para o crescimento desordenado da população local.

O projeto fundamentou-se nas propostas de Tubino (2001) sobre as "Dimensões Sociais do Esporte" e se referiu ao Esporte-Educação e Esporte-Participação através do interesse da criança pelo Esporte-Performance. No primeiro, as competições devem ter sentido e conteúdo educativos, visando à formação da cidadania. Fundamenta-se no conceito apresentado por Costa na resolução 01/ 89 (Brasil, 1989) o qual tem como finalidade democratizar e gerar cultura através de modalidades motrizes de expressão de personalidade do indivíduo em ação. Desenvolve uma estrutura de relações sociais recíprocas com a natureza, a sua formação corporal e as próprias potencialidades, preparando-o para o lazer e o exercício crítico da cidadania. Evita a seletividade, a segregação social e a hiper-competitividade, com vistas a uma sociedade livremente organizada, cooperativa e solidária. Tal prática esportiva como educação social pode ser um efetivo meio de formação de jovens, indispensável no desenvolvimento de suas personalidades e do processo de emancipação ${ }^{2}$.

Por outro lado, segundo Tubino (2001), o Esporte-Participação é referenciado com o princípio do prazer lúdico, que tem a finalidade de bem estar social dos participantes e relação íntima com o lazer e o tempo livre com propósito de descontração, de diversão, desenvolvimento pessoal e social. O valor social dessa prática é evidenciado na participação e nas alianças ou parcerias, fortalecendo a interação dos grupos e da comunidade. Interrelaciona-se com os caminhos democráticos, equilibrando o quadro de desigualdades nas oportunidades esportivas encontradas na dimensão do EsportePerformance.

\footnotetext{
${ }^{2}$ Em 1989 , os Jogos Escolares Brasileiros, com cerca de 3600 estudantes sob a responsabilidade da antiga Secretaria de Educação Física e Desportos, ligada ao Ministério da Educação, representada pelo saudoso Prof. Dr. Manoel José Gomes Tubino, juntamente com educadores brasileiros, desenvolveu o evento com base nos cinco princípios sócioeducativos: participação; cooperação; co-educação; integração; e co-gestão ou co-responsabilidade.
} 
Foram utilizados os recursos da recreação e os fundamentos básicos das modalidades esportivas para desenvolver as habilidades corporais e todas as qualidades físicas envolvidas como estratégia diferente para melhor atrair a atenção de crianças e jovens em idade escolar. Os que aderiram, mostraram-se motivados em participar da proposta de ensino-aprendizagem que também tinha o objetivo de sensibilizar os adeptos quanto à importância dos estudos.

Acompanhava-se o rendimento e a freqüência dos mesmos na escola e, para obter 0 comportamento mais adequado dos alunos, os estagiários interferiam, principalmente durante os jogos, nos momentos mais oportunos, e procuravam conscientiza-los quanto à necessidade de posturas mais educadas e maiores cuidados com os corpos dos colegas durante as brincadeiras para que todos saíssem das atividades felizes e sem traumas. Deste modo constituiu-se uma forma de inclusão social direcionada à criança para que ela pudesse adquirir condições de autonomia, emancipação e assim construir e conquistar seu espaço na sociedade em que vive. A estratégia de intervenção utilizada nos fez acreditar na nova proposta de trabalho da Educação Física dentro ou fora da escola.

O projeto "Cultura Corporal, Esporte e Lazer no Complexo do Alemão - RJ" funcionou como campo de observação e atuação para 12 universitários de Educação Física, sendo que 3 deles atuavam no turno da manhã (das $8 \mathrm{~h}$ às $9 \mathrm{~h}$ e das $9 \mathrm{~h}$ às $10 \mathrm{~h}$ ) e outros 3 no turno da tarde (das $14 \mathrm{~h}$ às $15 \mathrm{~h}$ e das 15 às $16 \mathrm{~h}$ ) às segundas, quartas e sextas feiras, enquanto o mesmo número de universitários praticavam as mesmas funções às terças e quintas. Atendiam especificamente às turmas de 7 a 9 anos dos primeiros horários de cada turno e finalizava os trabalhos com as turmas de 10 a 12 anos sob a supervisão e orientação presencial da Professora Ângela Tavares que também ministrava aulas na mesma Instituição de Ensino Superior em que seus auxiliares estudavam. Os extensionistas eram alunos da professora na IES e eram selecionados dentre os que mais se destacavam durante 0 cada semestre nas Disciplinas Ginástica II e Pesquisas e Práticas Pedagógicas III, as quais desenvolvia conteúdos de psicomotricidade e conteúdos fora do ambiente escolar, respectivamente. Os alunos que estavam nos últimos períodos do curso de licenciatura em Educação Física puderam cumprir a cargahorária de atividades complementares exigida para concluir o curso, freqüentando e coparticipando nas intervenções dos universitários menos experientes, apoiando-os diante de um público com tantas limitações emocionais, cognitivas e sociais de relacionamentos, com características marcantes de violência na forma de lidar com os colegas e suas limitações psicomotoras.

A violência doméstica, acrescida da guerra declarada entre a polícia e o tráfico de drogas que se enfrentavam diariamente na comunidade, deixava os seus moradores mais jovens confusos com relação aos valores que deviam seguir, além de violentos na hora de resolver seus problemas que despertavam a agressividade durante as práticas esportivas. Antes de qualquer objetivo motor havia a preocupação em educar os "ouvidos" daqueles que se inscreviam para freqüentar as aulas, pois chegavam violentos em excesso até mesmo na hora de brincar com os colegas. Então, foi preciso dar mais atenção à adaptação de cada novo adepto ao projeto nos cuidados com as falas, no trato com os colegas durante as atividades e com relação aos comportamentos em geral, sempre polêmicos.

Ao chegarem no recinto, aprendiam a cumprimentar com um simples "bom dia" ou "boa tarde" aos colegas e aos professores, pois assim todas as crianças passavam a entender a importância desse comportamento de polidez adquirido diante dos adultos e de outras crianças no dia-a-dia de cada um em sua comunidade quando eram elogiados pelos mesmos que aprovavam as novas atitudes. No início era preciso interferir muitas vezes durante as atividades por causa da falta de cuidados que acabavam machucando o adversário ou, até mesmo, o próprio companheiro, além de palavras de baixo calão presentes no ambiente, embora, na maioria das vezes, mostrassem desconhecer seus significados por estarem apenas repetindo o que ouviam diariamente. Posteriormente, mais adaptados às novas propostas de se relacionarem com as pessoas, já era possível alcançar posturas mais maduras e respeitosas que eles mesmos passavam a exigir um dos outros, caracterizando uma convivência mais pacífica e saudável. E quando recebíamos novos alunos, os antigos manifestavam-se como bons exemplos o que, diversas vezes, chegou a provocar constrangimento nos mais rebeldes que chegavam e buscavam adaptar-se e não serem tantas vezes chamados a atenção.

Foi muito gratificante saber que este projeto atendeu às necessidades dos responsáveis que se manifestavam durante as reuniões bimestrais e enfatizavam suas satisfações com o trabalho de educação desenvolvido, capaz de melhorar o comportamento das crianças. Foram utilizados os 
recursos de temas pedagógicos diferentes, desenvolvidos a cada bimestre para melhor esclarecer questões importantes para o universo da criança: "Tratar e Prevenir Questões de Saúde e Bem-Estar", "Drogas X Saúde - Remédios X Esportes", "Patriotismo, Direitos e Deveres do Cidadão", "Saúde para os Dentes, Corpo Sadio",
"A Paz Começa em Casa" e outros capazes de causar momentos de reflexão em cada "baixinho".

O trabalho desenvolvido está embasado no modelo pedagógico voltado para o redimensionamento epistemológico da Educação Física Escolar de Scarlet de Aguilar (2004) explicitado no quadro que se segue:

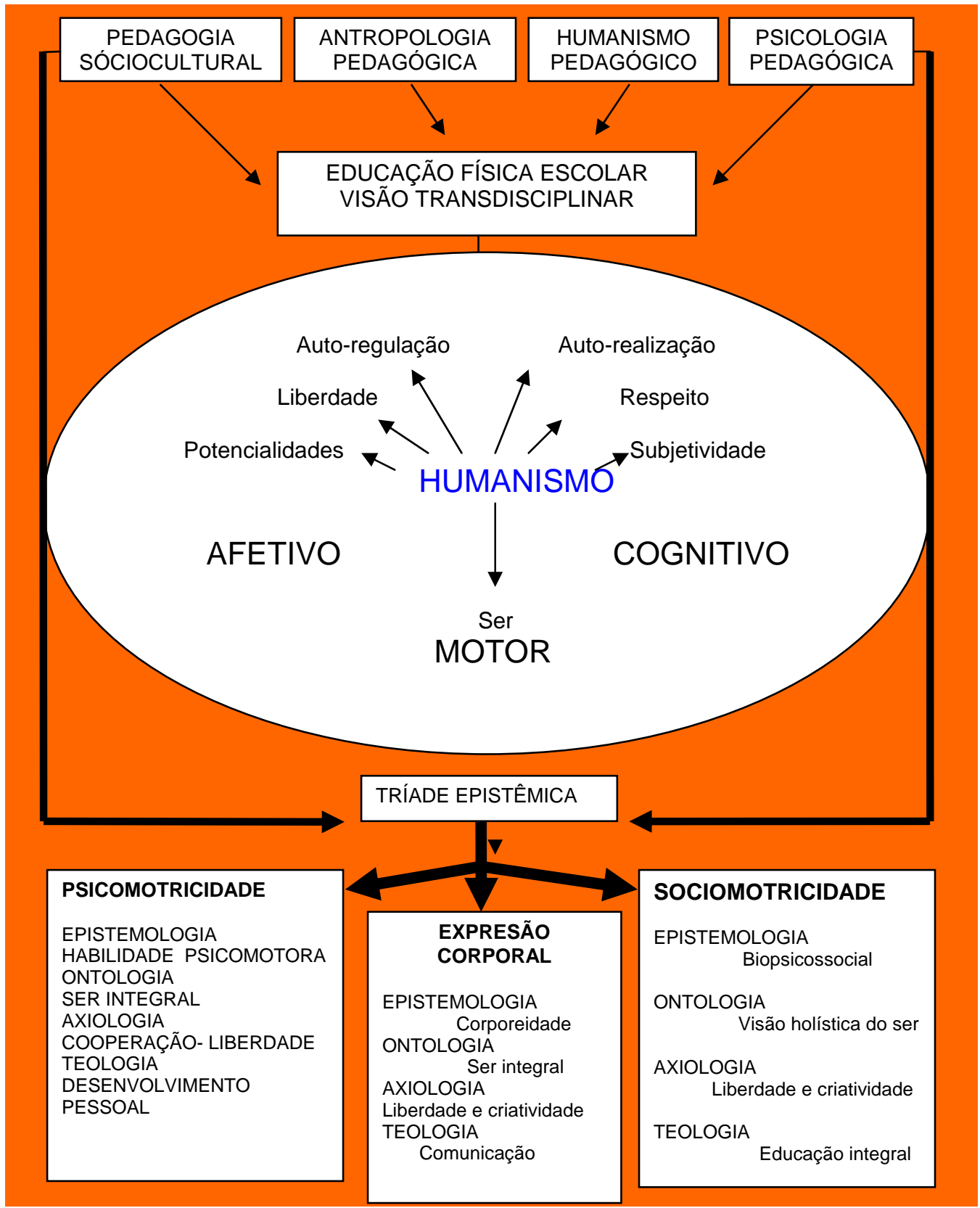

(AGUILARS, 2004)

De acordo com a dimensão humanística, o indivíduo do contexto social, biológico, político e cultural, interrelacionado com o ambiente, deve ser capaz de se posicionar, utilizando o seu potencial cognitivo, afetivo e motor que lhe permitam resolver problemas.

A teoria humanística visa o bem-estar do ser, a liberdade e a criatividade que deriva do modelo pedagógico como a dimensão epistemológica da Educação Física. Com esta visão, origina-se o desenvolvimento holístico do indivíduo; um profissional comprometido com base na concepção humanística; pensamento à frente da globalização do conhecimento; participação ativa das atividades sócio-acadêmicas das áreas do conhecimento; implantação dos princípios 
pedagógicos da Educação Física; prática pedagógica inovadora; interpretação da dinâmica do ambiente escolar; professor disposto a mudanças; práxis pedagógicas proativas baseadas em processos de mudanças permanentes; um ser global capaz de se desenvolver à medida que cresce e modifica a própria visão do mundo com o seu significado reconstruído a cada momento. (AGUILARS, 2004).

Ao se abordar os saberes da psicomotricidade, sociomotricidade e expressão corporal no projeto, unificam-se os conhecimentos da Educação Física possibilitando emergir o modelo pedagógico em sua dimensão epistemológica.

Em sua práxis pedagógica, a psicomotricidade propicia o desenvolvimento integral da criança através de seu corpo e suas vivências com a subestimação de técnicas de movimento para cuidar de valores humanos como: criatividade, aceitação própria, socialização, conjunto de experiências em sua educação, habilidades, qualidades básicas e globais, que dão lugar à motricidade humana.

A sociomotricidade, pedagogia da conduta motriz analisa as conquistas do indivíduo com princípios humanísticos e axiológicos para valorizar a busca de novas estruturas que permitem explorar a dimensão motora em cooperação ou em antagonismos, viabilizar formas de expressão, possibilidades motoras inusitadas, percepção motriz em situações lúdicas coletivas e espontaneidade corporal. $\mathrm{Na}$ dimensão afetiva, a sociomotricidade propicia a auto-estima, favorece a motivação, educa para a liberdade gerando autonomia e responsabilidade em tomar decisões, situações de alegria, prazer, amizade e bem-estar no coletivo.

A expressão corporal do indivíduo integra a linguagem da dimensão motora, cognitiva e afetiva que desenvolve sua personalidade $\mathrm{e}$ maneira de se relacionar com o mundo que o cerca. Os gestos transcendem os limites da linguagem cultural do homem que toma consciência do próprio corpo por meio da concentração e relação; adaptação do gesto em relação ao ritmo e sua intencionalidade que valoriza as diversidades culturais e lúdicas; a riqueza do movimento como um meio de comunicação e criatividade. (AGUILARS, 2004).

\section{Metodologia}

A recreação e as atividades esportivas com variados estímulos eram desenvolvidas para que os educandos desenvolvessem a destreza motora mais complexa, buscando atender, desta forma, desde os menos habilidosos, com exercícios simples, até os mais hábeis.

Eram lançados desafios audaciosos, porém sem a exigência de que atingissem aos objetivos imediatos de cada exercício, como acontece no esporte de alto rendimento. As individualidades biológicas de cada aluno do projeto eram respeitadas e, assim, o nível de aquisição no aproveitamento técnico e na realização dos movimentos específicos em cada fundamento básico das modalidades trabalhadas apresentava um ritmo adequado de acordo com as limitações de cada um.

Os materiais didáticos utilizados eram basicamente: as bolas de borracha, cones e cordas, além dos próprios corpos das crianças, concebidos como unidades básicas de significado existencial que dão suporte às emoções e expressões de movimentos, capazes de favorecerem as comunicações humanas e, como tal, auxiliarem na realização das brincadeiras.

A prioridade para se conquistar grandes progressos nas habilidades corporais de cada criança foi respeitar a individualidade biológica. Tais habilidades poderiam servir como "passaporte" para que o aluno tomasse gosto pelo esporte e se motivasse devido ao possível sucesso na realização de seus movimentos para que pudessem apresentar recursos corporais capazes de aplicá-los durante o jogo.

Os exercícios educativos específicos que aconteciam no início das aulas facilitavam a relação com o seu elemento principal mediador da atividade lúdica, a bola. Tal abordagem propiciou o alcance de um dos objetivos específicos de desenvolver qualidades físicas através de jogos que envolviam modalidades de esportes diferentes na mesma aula e auxiliou os professores na superação dos desafios para cada criança com propriedade, sem medos ou riscos, com a prudência necessária para atingir, com sucesso, os objetivos do(s) jogo(s) que mais se identifique.

As vivências motoras bem sucedidas da criança poderão ser um credenciamento conquistado para um possível sucesso na 
performance desejada posteriormente, durante a adolescência, quando se interessar mais por um determinado esporte.

Com a concepção de uma educação motora que tem a visão biopsicossocial do indivíduo aplicada, a ação pedagógica e psicológica utiliza o movimento com o fim de normalizar ou melhorar o comportamento do aluno. Este benefício facilita 0 desenvolvimento da personalidade, ajuda na adaptação a obstáculos do meio sócio-cultural e, em especial, àqueles representados pelas aprendizagens escolares. $\mathrm{O}$ esquema corporal amadurecido desde a primeira infância oferece à criança as noções das partes de seu corpo e de suas relações, as quais vão formando a própria imagem interna e externa que estão em contato com o meio ambiente. A imagem corporal não está pré-formada, ela é, segundo Mucchielli (LE BOULCH, 1987), uma estrutura "estruturada" que possibilita um conjunto de sensações referentes ao próprio corpo, além da representação mental que o indivíduo tem de si mesmo, como resultado da soma total de suas experiências.

Para Le Boulch, a lateralidade caracteriza-se de acordo com a predominância motora que incide sobre os segmentos direitos ou esquerdos do corpo. Os espaços motores correspondentes ao lado direito e ao lado esquerdo não são homogêneos e esta distinção vai determinar o lado do corpo dominante para a função motora. A lateralidade, qualidade psicomotora importante no amadurecimento das habilidades corporais, trabalha a capacidade do indivíduo em melhorar o lado do corpo não dominante, buscando igualar o mesmo nível de controle e força de suas duas partes laterais, com os membros superiores e inferiores, permitindo-Ihe estabelecer relações espaciais.

Portanto, lateralidade, esquema e imagem corporal, sendo bem estimulados, podem ser decisivos para o domínio do corpo e as qualidades físicas. Por isso, as atividades que tiveram uma atenção especial dentro do planejamento foram: força, agilidade, velocidade, coordenação, equilíbrio, ritmo, flexibilidade e descontração. Tubino \& Macedo (2006) consideram-nas atributos treináveis que permitem adaptações do organismo o qual obedece a uma rotina que educa e transforma o corpo para adquirir um lastro fisiológico ao longo do tempo. Tais qualidades, dizem os autores, devem ser direcionadas em qualquer programa na área de Educação Física e de Esportes.

\section{Descrição das atividades}

$\mathrm{Na}$ proposta do projeto de "Recreação Esportiva" realizado no Complexo do Alemão exploravam-se as brincadeiras tradicionais e novas tarefas mais complexas eram lançadas para aumentar o nível de dificuldade, promover desafios, exigir criatividade das crianças e esgotar os seus recursos para tentarem acompanhar a turma.

Para algumas atividades sem bola, durante 0 aquecimento, utilizava-se de: "O Mestre" quando era ordenado aos alunos que executassem rolamentos para frente, para trás, de um lado para o outro com o objetivo de oferecer o maior contato possível com o chão; "Batatinha frita 1, 2, 3" lançava-se objetivos cada vez mais difíceis antes de cada rodada, pois todos eram avisados que deveriam estar com, pelo menos, uma das mãos no chão, com um dos joelhos, com a cabeça, um dos ombros no momento em que ele acabava de contar. Assim, eles sabiam que teriam menos tempo para correr em direção ao seu destino para poder dar tempo do professor virar e não ver ninguém se mexendo. As várias versões de "O gato e o rato" foram utilizadas sempre na intenção de inovar comandos problematizadores e impor limitações; diversos piques e tipos de estafetas quando dividia-se o grupo em 4 ou 6 partes iguais para que todos fossem solicitados mais vezes e não se deixasse em evidência o grupo que perdia a disputa, o que poderia acontecer, às vezes, por causa de um mesmo aluno menos ágil e com maiores dificuldades de deslocamento, se fosse aplicado apenas a duas equipes.

No segundo momento da parte inicial, utilizava-se o elemento principal do jogo: a bola, que fascina os olhos de qualquer criança como um instrumento mediador que exigia habilidades de controle, de condução e, quando chegava a uma altura maior, assustava a criança que se sentia ameaçada, mas tentava vencer o medo de ficar embaixo e ainda procurava segurá-la. Desafiava a relação da criança com o próprio corpo diante das novas experiências lançadas a cada obstáculo vencido e, em seguida, tinha que conciliar as dificuldades já identificadas, com a bola. 
Na parte principal da aula com bola, utilizavase os desafios corporais, quando era jogado o "cabeçobol": as crianças deitadas em decúbito frontal e apoiada sobre mãos e pés eram divididas em duas equipes, cada equipe atrás de uma linha de gol e elas poderiam invadir o campo desde que tocassem apenas com a cabeça na bola. Se a bola tocasse em qualquer outra parte do corpo de alguém dentro da área de jogo, fazia gol contra, mas o objetivo de cada time era fazer com que a bola fosse impulsionada e ultrapassasse a linha de gol do campo adversário. E, baseado nessas regras, 0 professor determinava qual seria a próxima parte do corpo que poderia tocar na bola para evitar que a mesma ultrapasse a linha que caracterizaria o gol.

O voleibol sentado dava ênfase à necessidade de posicionar o corpo embaixo da bola para executar o toque; "Câmbio sentado" tinha o objetivo de não deixar a bola cair no seu campo e todos deveriam tocá-la antes da mesma ser arremessada para o lado adversário; Todos de pé, como um jogo cooperativo, espalhados pelo espaço disponível deveriam tocar na bola com o pé esquerdo apenas uma vez antes que todos os outros também participassem, depois trocassem para o pé direito, calcanhar esquerdo, depois o direito, tocassem com a mão esquerda fechada, mão direita, glúteos, cotovelo esquerdo, depois o direito, cabeça e ombros, pernas e coxas, ou seja, a lateralidade estava sempre valorizada quando eram trabalhados os lados direito $\mathrm{e}$ esquerdo do corpo. "Queimado" e suas variações possibilitava lançar a bola apenas com a mão esquerda e depois somente com a mão direita, para desenvolver os membros superiores, autocontrole sem as especializações do treinamento, sem limitar a criança que precisava explorar as suas potencialidades.

Assim, de acordo com a proposta de trabalho, a idéia foi desenvolver os fundamentos básicos das modalidades de esportes tradicionais como os tipos variados de passes do handebol, do futsal, do basquetebol, do voleibol. É importante frisar que antes ou depois de cada movimento com a bola a criança deveria ser capaz de executar um rolamento, um salto com pirueta ou alguns outros fundamentos da ginástica artística como estratégia de buscar o domínio do corpo com ou sem bola. No caso dos fundamentos do futsal, valorizava os equilíbrios estático, dinâmico e recuperado como principal detalhe a ser aprimorado para que a criança pudesse liberar do chão, o pé que iria tocar na bola sem perder o domínio do próprio corpo.

O método misto de aula era o mais utilizado, quando o objetivo específico em cada exercício educativo para o corpo, era vencer as dificuldades de execução em cada fundamento. A progressão pedagógica do exercício mais simples ao mais complexo atendia à realidade observada e às dificuldades encontradas em sua realização. O plano de aula era alterado para melhor atender às necessidades do aluno ou do grupo. Quando necessário, era aplicado um educativo para um determinado aluno ter seu sucesso garantido em suas investidas em cada atividade, procedimento que garantia a evolução de seu desempenho diante da turma.

$\mathrm{Na}$ última parte da aula, o nível de aprendizado era avaliado durante o jogo. Jogavam recreando sem as exigências de ter que produzir resultados e movimentos estereotipados com liberdade para conduzir a bola, realizar o passe, o chute, o arremesso, a cortada e a defesa. Assim era possível explorar e conhecer todos os esquemas do corpo, o seu campo de ação e a forma, assim como a velocidade de seu raciocínio para tomar as decisões acertadas ou não, pois o aluno dependia da precisão da jogada. O jogo sempre exigia muita concentração porque combinava os fundamentos de modalidades de esportes diferentes. A turma dividida em dois grupos iguais e cada equipe progredia com a bola nos pés e, para fazer o ponto, deveria segurá-la com as mãos e arremessá-la para a cesta quando chegasse ao garrafão do basquete; driblava e passava a bola com as mãos obedecendo aos fundamentos do handebol ou do vôlei e, na hora de marcar o ponto, o jogador deveria estar dentro da área de futsal para chutar e tentar fazer o gol; e outros jogos adaptados utilizando somente o lado direito ou o lado esquerdo do corpo, dependendo da determinação do professor.

\section{Resultados e Discussão}

Sabe-se que em muitas aulas de iniciação esportiva valorizam-se apenas os mais habilidosos e normalmente a criança acaba vivenciando as experiências de apenas uma modalidade escolhida. Os profissionais que ministram as aulas acabam determinando as 
posições específicas de cada jogador em função das necessidades de suas equipes, engessando ainda mais a participação de cada criança.

Além de buscar um convívio de respeito entre os alunos, suas limitações e as dos colegas, a "Recreação Esportiva" valorizou a participação de todos, ajudou a superarem frustrações de performance nos fundamentos de modalidades diferentes na mesma aula, melhorou os domínios cognitivo, afetivo-social e psicomotor através da recreação presente na prática esportiva descontraída. Os habilidosos no futsal encararam desafios diferentes durante a realização dos fundamentos do voleibol e, desta forma, todos conseguiram momentos de valorização diante do grupo, além de melhorarem a auto-estima e despertarem interesses e habilidades em outras modalidades que nem tinham se dado a chance de experimentar. Foi observado um prazer, um espírito cooperativo e uma alegria constante em praticar movimentos específicos de uma determinada modalidade. Variaram-se os estímulos sem ficar cansativo para a criança que pôde levar consigo experiências motoras, coragem e confiança muito importantes no seu quotidiano.

Para os futuros profissionais de Educação Física, o mais importante era que entendessem que a inclusão social para o indivíduo em idade escolar aconteceria somente se o mesmo estivesse na escola, investindo em seu futuro e aprendendo a ser um cidadão conhecedor de seus direitos e deveres para terem mais chances diante da sociedade em que vivem. Dos 278 inscritos no projeto, 108 crianças freqüentavam as aulas de Recreação Esportiva e, dessas, 16 foram identificadas fora da escola. Durante as reuniões bimestrais, seus responsáveis eram questionados sobre a difícil situação de seus filhos e em todos os casos os responsáveis mostraram-se muito agradecidos pelo comprometimento do projeto em ajudá-los a resolver o problema, após tê-los encaminhados à $4^{a}$ CRE (Coordenadoria Regional de Educação) que atende às escolas do bairro. $E$ quanto às crianças, eram os que mais precisavam da oportunidade de escutar um recreador / educador capaz de mediatizar a consciência do valor dos estudos em suas vidas.

A proposta foi estruturada como projeto de extensão universitária o que permitia aplicação direta dos conhecimentos adquiridos na literatura pelos universitários para combinar suas práticas pedagógicas com abordagens voltadas para uma integração humanística de formação do ser, do conhecer, do fazer e do conviver. A visão do profissional que irá trabalhar na escola, quando favorecida pela experiência do conhecimento sobre esta complexa área onde irá exercer sua intervenção, terá que se voltar para uma educação que privilegie o indivíduo como parte ativa e participativa de seu processo de aprendizagem e que reconstrua 0 seu conhecimento para alcançar a sua própria aprendizagem.

As práticas da Educação Física vão muito além de trabalhar o corpo da criança para desenvolver suas habilidades motoras, devem auxiliar na educação do jovem morador da área de risco para potencializá-lo através das atividades esportivas e recreativas presentes na Recreação Esportiva, buscando minimizar os possíveis problemas para estimulá-lo constantemente a vencer os obstáculos na luta por novos ideais de vida como cidadão.

\section{Referências}

AGUILARS, S. K. Modelo pedagógico para La redimensión epistemológica de la educación física escolar. In La actividad física en el desarrollo humano. Caracas: Universidad Pedagógica Experimental Libertador, 2004, p.179.

BRASIL, LEI No9.696, de $1^{\circ}$ de setembro de 1998. Disponível em

http://www.confef.org.br/extra/juris/mostra lei.asp ?ID=38. Acesso em 20 de dezembro de 2009.

BRASIL, Ministério da Educação, Conselho Nacional de Desportos. Resolução n. 01/ 89. Brasília: CND, 1989.

D'AMICO, R. L.; D'AMICO, C. La actividad física como elemento básico del sano desarrollo del ser humano. In La actividad física en el desarrollo humano. Caracas: Universidad Pedagógica Experimental Libertador, 2007, p.11.

FERREIRA, Vanja. Educação Física, Recreação,Jogos e Desportos. Rio de Janeiro: $2^{\mathrm{a}}$ edição: Sprint, 2006.

LE BOULCH, Jean. Rumo a Uma Ciência do Movimento Humano. Porto Alegre: Artes Médicas, 1987.

PARLEBAS, Pierre. Elementos de sociologia del deporte. Málaga (Spain): Junta de Andalucia/ 
Universidad Internacional Deportiva de Andalucia, 1988.

SCHILLER, F. A educação estética do homem numa série de cartas. São Paulo: Iluminuras, 1995.

TUBINO, M. Dimensões Sociais do Esporte. 2. Ed. Revista - São Paulo: Cortez, 2001 (Coleção Questões da Nossa Época; v. 11).

TUBINO, M. e MACEDO, M. Qualidades Físicas na Educação Física e nos Esportes. Rio de Janeiro: Shape, 2006.

BRASIL, MINISTÉRIO DE EDUCAÇÃO, SECRETARIA DE EDUCAÇÃO FÍSICA E DESPORTOS. Carta brasileira de esporte educacional. Brasília: SEED,MEC,1989.

CONFERÊNCIA DAS NAÇÕES UNIDAS SOBRE MEIO AMBIENTE E DESENVOLVIMENTO

(CNUMAD).Agenda 21. Rio de Janeiro: 1992. Disponível em

http://www.ecolnews.com.br/agenda21/index.htm. Acesso em 20 de dezembro de 2009.

CONSELHO FEDERAL DE EDUCAÇÃO FÍSICA. Carta brasileira de educação física (2000). Em http://www.confef.org.br/extra/conteudo/default.as p?id=21. Acesso em 20 de dezembro de 2009.

FÉDÉRATION INTERNATIONALE D'EDUCATION PHYSIQUE. Manifesto mundial de educação física FIEP 2000. Foz de Iguaçu: FIEP, 2000.

INTERNATIONAL COUNCIL OF SPORT SCIENCE AND PHYSICAL EDUCATION. World Summit on Physical Education. Berlin: ICSSPE, 1999.

PANATHLON INTERNATIONAL. Carta dos direitos da criança no esporte. Avignone: Panathlon, 1995.

UNESCO. Carta internacional de educação física e esporte. Paris:UNESCO, 1978.

UNESCO. Declaração de Punta del Este do III Encontro de Ministros e Responsáveis pelo Esporte e Educação Física. Punta del Leste: UNESCO, III MINEPS, 1999.

UNESCO. Manifesto 2000 - Por uma Cultura de Paz e Não Violência. Paris: UNESCO, 1998.

Disponível em http://www.comitepaz.org.br/o manifesto.htm. Acesso em 20 de dezembro de 2009.
Agradecimentos: Prof. Ms. Rogério de Carvalho Moreira, Profa Ms. Rosane Cordeiro e Marietta Capella Tavares (IN MEMORIAN)

Endereço:

Ângela Ferreira Tavares

Rua Uruguai, 89 Extensão do Bosque.

Rio das Ostras RJ Brasil

28890-000

e-mail: angelaf.tavares@hotmail.com

Recebido em: 12 de agosto de 2009.

Aceito em: 23 de novembro de 2009.

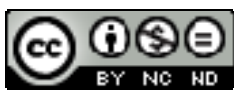

Motriz. Revista de Educação Física. UNESP, Rio Claro, SP, Brasil - elSSN: 1980-6574 - está licenciada sob Licença Creative Commons 